\title{
Enhancing social support and knowledge perception decreases patient delay in breast cancer
}

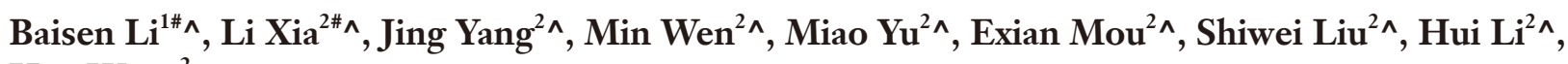 \\ Hao Wang ${ }^{2} \wedge$
}

${ }^{1}$ Department of Radiotherapy Center, Sichuan Cancer Hospital \& Institute, Sichuan Cancer Center, School of Medicine, University of Electronic Science and Technology of China, Chengdu, China; ${ }^{2}$ Department of Breast Surgery, Sichuan Cancer Hospital \& Institute, Sichuan Cancer Center, School of Medicine, University of Electronic Science and Technology of China, Chengdu, China

Contributions: (I) Conception and design: B Li, L Xia, H Wang; (II) Administrative support: H Li, J Yang; (III) Provision of study materials or patients: M Wen, M Yu; (IV) Collection and assembly of data: E Mou, S Liu; (V) Data analysis and interpretation: B Li, L Xia, H Wang; M Wen; (VI) Manuscript writing: All authors; (VII) Final approval of manuscript: All authors.

\#These authors contributed equally to this work.

Correspondence to: Hao Wang. Department of Breast Surgery, Sichuan Cancer Hospital \& Institute, Sichuan Cancer Center, School of Medicine, University of Electronic Science and Technology of China, Chengdu 610000, China. Email: Unique214@163.com.

Backgroundz Patient delay commonly appears in breast cancer (BC), but the findings for influential factors may be contaminated by recall bias. The real factors in patient delay (divided into appraisal delay and utilization delay) for women with BC urgently need to be objectively analyzed for preventing the progression of this disease.

Methods: Women meeting strict inclusion and exclusion criteria were asked to fill in a questionnaire, which included three sections of sociodemographic characteristics, medical history, and knowledge of BC. Later on, the outcomes were processed according to the verification of $\mathrm{BC}$ by pathological diagnosis. Then, multiple linear regression was conducted to analyze the potential factors of the delay and to explore their relations between these factors and BC.

Results: Appraisal delay is the leading component of patient delay. Appraisal delay's time distribution of a higher percentage at delay time 0-29 and >360 days, while other delay time occupies lower percentage, which is highly consistent with that of patient delay, while utilization delay mainly occurs in the 0-29 days period. Concerning the influential factors for the different phases of delay, age $(\mathrm{P}=0.051, \mathrm{P}=0.035$ separately in appraisal and patient delay), residential address $(\mathrm{P}=0.036, \mathrm{P}=0.010)$ and symptom disclosure to others $(\mathrm{P}=0.015, \mathrm{P}=0.015)$ led to a decrease of appraisal and patient delay. However, reasons for first medical consultation $(\mathrm{P}=0.033, \mathrm{P}=0.006)$ and knowledge of $\mathrm{BC}(\mathrm{P}=0.027, \mathrm{P}=0.002)$ would accelerate appraisal and patient delay. Many factors related to hospitals, such as hospital category for first medical consultation $(\mathrm{P}=0.030)$ and examinations for first medical consultation $(\mathrm{P}=0.055)$ would reduce utilization delay.

Conclusions: Obstacles in medical consultation for younger women should be removed, and early interventions are needed to avoid progression of BC.

Keywords: Patient delay; breast cancer (BC); Chinese; delay-related factors

Submitted Mar 04, 2021. Accepted for publication Jun 16, 2021.

doi: $10.21037 /$ gs-21-227

View this article at: https://dx.doi.org/10.21037/gs-21-227

\footnotetext{
^ ORCID: Baisen Li, 0000-0003-3674-061X; Li Xia, 0000-0002-3676-7401; Jing Yang, 0000-0002-3730-4193; Min Wen, 0000-0001-5623-

7662; Miao Yu, 0000-0002-9445-8447; Exian Mou, 0000-0002-7714-1261; Shiwei Liu, 0000-0002-6766-7518; Hui Li, 0000-0002-04518419; Hao Wang, 0000-0002-2725-5674.
} 


\section{Introduction}

Breast cancer (BC) ranks first among the incidence of female malignant tumors worldwide. According to the data from GLOBOCAN 2012, produced by the International Agency for Research on Cancer (IARC) (1) that there were approximately 4,292,000 new Chinese cases of cancer in 2015, in which BC, the country's leading cause of cancer deaths among women under the age of 45 , accounted for about $15 \%$ of total cases. Due to education, religious beliefs, and other reasons, $\mathrm{BC}$ is considered to be an incurable disease, whose treatment has been associated with a loss of femininity $(2,3)$. Therefore, patients with $\mathrm{BC}$ often choose to delay medical consultation and treatment, which could greatly lead to more complications and progression of the disease.

Delaying medical consultation, also known as patient delay, for patients with BC is a serious issue in China. Patient delay, which is defined as the duration from self-discovered symptoms to the first consultation, is determined by factors of cognition, emotion, social relationships, living situations, and the interactions of these factors (4). This concept can be subdivided into appraisal delay (period between symptom detection and decision for consultation) and utilization/illness delay (period between decision for consultation and actually receiving later consultation) (5). An observational study in 2013 (6) showed that the 5-year survival rate for BC is only $80 \%$ if the delay exceeds 6 weeks before acquiring surgery, as compared with $90 \%$ for patients with a delay of less than 2 weeks. Two retrospective studies included populations of those who had surgery followed by chemotherapy based on SEER and NCDB showed that with per month of preoperative delay, patients' risk of death increased by $9 \%$ to $10.4 \%$ $(7,8)$. Richards et al. (9) conducted a systematic evaluation of 87 studies and concluded that a delay of 3 months would have an impact on the long-term survival of patients. In most studies, medical delay of more than 90 days (3 months) was defined as prolonged patient delay (10-12). Therefore, it is critical to eliminate the factors of prolonged patient delay and improve the quality of life for patients with BC.

Thus, a questionnaire-based interview was conducted for women who needed confirmation of breast abnormality by pathological diagnosis in Sichuan Province, China. By implementing this evaluation before diagnostic verification, we effectively reduced recall biases and explored the characteristics of patient delay in women with BC. Improving the awareness of $\mathrm{BC}$ and taking active interventions when suspicious symptoms appear are necessary to improve patient prognosis. We present the following article in accordance with the STROBE reporting checklist (available at https:// dx.doi.org/10.21037/gs-21-227).

\section{Methods}

\section{Patient enrolment and procedure}

Mandarin-speaking or Sichuanese dialect-speaking women, aged $\geq 18$ years, lucid, with normal comprehension and verbal expression, were recruited in the breast specialist outpatient clinics of Sichuan Cancer Hospital \& Institute, Sichuan Cancer Center, School of Medicine, University of Electronic Science and Technology of China, Chengdu. Patients, who had been diagnosed before with a Breast Lesion of Imaging-Reporting and Data System (BI-RADS) by mammography or color Doppler ultrasonography, with further confirmation by pathological diagnosis, were eligible for this study. Women who refused to participate, who did not have the ability to comprehend and complete the questionnaire, whose prior breast abnormality had been diagnosed as $\mathrm{BC}$ or which could not be verified by pathological diagnosis, were excluded. All procedures performed in this study involving human participants were in accordance with the Declaration of Helsinki (as revised in 2013). The study was approved by Ethical Committee of Sichuan Cancer Hospital (No. SCCHEC-02-2021-033) and informed consent was taken from all the patients.

Between April 20, 2014, and June 20, 2019, women meeting the inclusion and exclusion criteria above were enrolled in the study. While awaiting their diagnostic confirmation in breast clinics, the recruited women were interviewed and asked to fill in the questionnaires after having signed informed consent. The questionnaire included three sections of sociodemographic information, medical history, and knowledge of BC. The scheduling of the questionnaire was intended to minimize recall bias, post hoc rationalization of help-seeking behavior, and selective recall. The investigator would ghostwrite the questionnaire in cases where the woman could not do so unaided due vision impairment, education, etc. The questionnaires were immediately collected. The responses to questionnaires from patients were processed and analyzed according to the verification of $\mathrm{BC}$ by pathological diagnosis (Figure 1).

\section{Measures}

\section{Sociodemographic characteristics}

The information on patients' age, religion, education, 


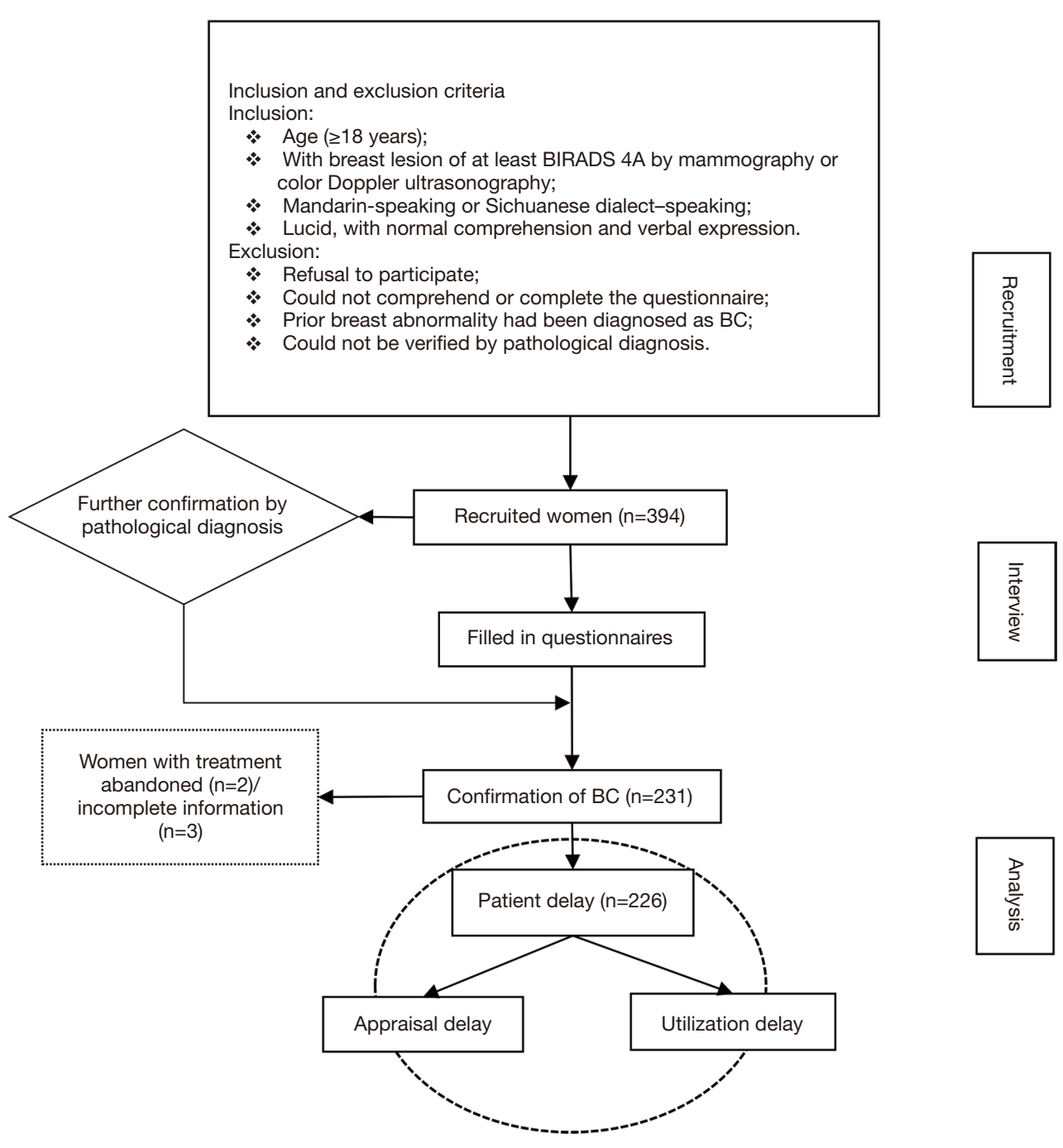

Figure 1 Research procedure of the study.

residential address, family, occupation, income, and type of medical insurance was collected.

\section{Medical history}

The questionnaire was designed based on the patient's medical history and included items on family history of $\mathrm{BC}$, routine breast examination, symptom disclosure to others, underlying disease, hospital category for first medical consultation, examinations for first medical consultation, previous corresponding medical help-seeking behaviors, and others. Further emphasis was placed on medical consultation behaviors, which included items on symptoms, date, and manner of the patient's first discovery of breast abnormality (whether the lesion was benign or cancerous by self-evaluation), and the date of patient's decision for medical consultation and actual consultation. Thus, appraisal delay (period between symptom detection and decision for consultation), utilization delay (period from deciding to receive consultation and actually being consulted) and patient delay (sum of appraisal delay and utilization delay) were calculated. The conventional cutoff of 90 days (3 months) $(12,13)$ to categorize these delays into normal or prolonged was adopted.

\section{Knowledge of BC}

The patients' comprehension of basic knowledge, screening, risk factors, and typical symptoms and signals of BC was examined. Women were asked the following: "Will BC destroy normal tissue (sy1) or proliferate (sy2)?" and "Is BC 
a malignant tumor (sy3)?" in the Basic Knowledge section. They were further asked the following: "Do you think screening can detect BC early (sc1)?", "Do you think early detection of BC improves survival (sc2)?", "Do you know about the time (sc3) or the technique (sc4) of breast selfexamination?", and "Do you consider mammography (sc5) or a doctor's examination (sc6) to be a screening method for BC?" in the Screening section. Women were further queried the following: "Is the occurrence of $\mathrm{BC}$ is related to [age (r1)], [heredity (r2)], [obesity (r3)], [endocrine disorder $(\mathrm{r} 4)$ ], [unhealthy lifestyle ( $\mathrm{r} 5)$ ], [prior $\mathrm{BC}$ in the other side (r6)], [benign breast disease (r7)], [exposure to high doses of radiation or prolonged environmental contamination (r8)], [estrogen ( $\mathrm{r} 9)$ ] or [number of pregnancies, age of bearing or duration of lactation (r10)]?" in the Risk Factors section . Finally, they were asked the following "Do you regard [breast lump (t1)], [axillary lump (t2)], [breast pain (t3)], [nipple change ( $t 4)$ ], [shape change of breast ( $t 5)$ ] or [skin change of breast (t6)] as typical symptoms and signals of BC?". Patients could respond "yes", "no" or "I don't know" in response to each of these queries.

\section{Statistical analysis}

In this study, $t$-test, analysis of variance (ANOVA), chisquare test, rank-sum test or other methods were chosen according to data type and used to perform univariate analysis on the collected information so as to screen out potential factors (a $\mathrm{P}$ value $\leq 0.2$ was taken as the inclusion standard), which could affect delay of medical consultation (appraisal delay, utilization delay, and patient delay). For example, differences between groups were assessed using either Student's $t$-test or one way ANOVA for continuous variables (such as Age, Routine breast examination), and chi squared test or rank-sum test for categorical variables (such as Residential address, Knowledge of BC). Then, multiple linear regression was conducted to analyze the potential factors and to explore their relation with BC.

The SPPS 22.0 (IBM Corp.) was used for statistical analysis. All tests were 2 -sided and $\mathrm{P}$ value $<0.05$ was regarded as clinically significant.

\section{Results}

\section{Participant characteristics}

Of the 394 women enrolled, 168 (42.64\%) were verified with fibroadenoma, intraductal papilloma, breast cystic hyperplasia, and concomitance of 2 or more of the diseases above, while $226(57.36 \%)$ were subsequently confirmed to have BC [not including patients with treatment abandoned $(n=2)$ or incomplete information $(n=3)]$.

Overall, the age of participants with $\mathrm{BC}$ ranged from 27 to 71 years (mean $=49.21, \mathrm{SD}=10.03$ ). Most patients lived in Sichuan Province (93.36\%, both urban and rural areas), had no religious affiliation $(98.23 \%)$, and had access to at least one type of medical insurance (99.57\%). Most of the women completed junior high school $(61.07 \%)$, raised 1 child (64.16\%), were employed (55.76\%, including bluecollar and white-collar jobs) and had an average monthly per capita income of CNY 2,000-3,999 (51.77\%) (Table 1).

In the terms of medical history, only a portion of the women had a family history of BC (5.31\%). Fewer than half the patients had undergone a routine breast examination (26.11\%), while the majority had disclosed their breast symptoms to others $(83.63 \%)$ and had been examined by color Doppler ultrasonography $(75.71 \%)$ for the first medical consultation in a primary health institution (56.19\%) due to concerns about their health $(78.43 \%)$. Some patients indicated being occupied by other life priorities $(19.87 \%)$ as the reason of not obtaining further confirmation, and that the majority of symptoms were not painful and therefore not considered to be serious (57.58\%). When they sought medical consultation, most women had breast lump/pain (69.64\%) and were fearful (16.50\%). Most patients were diagnostically confirmed as stage 0-II BC (74.12\%; Table 2). More than half of the patients showed mastery of basic knowledge ("sy1" $=73.66 \%$, "sy2" $=76.79 \%$, and "sy3" $=79.46 \%$ ), elementary screening ("sc1" $=77.23 \%$ and "sc2" $=83.04 \%$ ) and typical symptoms and signals of BC ("t1" $=71.88 \%$, " $\mathrm{t} 2 "=62.05 \%, " \mathrm{t} 3 "=63.39 \%$, " $\mathrm{t} 4 "=66.52 \%$, " $\mathrm{t} 5 "=65.18 \%$, and " $\mathrm{t} 6 "=58.93 \%)$. Fewer than $60 \%$ of women answered "yes" in risk factors "r1-10", among which response "yes" is fewer when it comes to "r2" and " $\mathrm{r} 3$ ", the proportion is $39.73 \%$ and $39.29 \%$ respectively. And few had learned about professional screening ("sc3.1" $=38.84 \%$, "sc $3.2 "=32.59 \%$, "sc4" $=42.41 \%$, and "sc5" $=53.13 \%$; Figure 2).

\section{Delay durations of medical consultation}

Appraisal day [median 9 days; interquartile range (IQR) 112.75 days; range $0-2,199$ days], utilization delay (median 2; IQR 11; range 0-734), and patient delay (median 28.5; IQR 143.5; range $0-2,206$ ) of women with $\mathrm{BC}$ were separately calculated according to the collected data. In addition, both 
Table 1 Sociodemographic characteristics of women with BC

\begin{tabular}{|c|c|}
\hline Characteristics & $\mathrm{n}=226(\%)$ \\
\hline \multicolumn{2}{|l|}{ Age (years) } \\
\hline Mean \pm SD & $49.21 \pm 10.03$ \\
\hline \multicolumn{2}{|l|}{ Religion } \\
\hline Yes & $4(1.77)$ \\
\hline No & $222(98.23)$ \\
\hline \multicolumn{2}{|l|}{ Education } \\
\hline Primary or below & $71(31.42)$ \\
\hline Junior high & $67(29.65)$ \\
\hline Senior high/Technical secondary & $45(19.91)$ \\
\hline Bachelor/college or above & $43(19.03)$ \\
\hline \multicolumn{2}{|l|}{ Number of children } \\
\hline 0 & $0(0)$ \\
\hline 1 & $145(64.16)$ \\
\hline 2 & $74(32.74)$ \\
\hline$\geq 3$ & $7(3.10)$ \\
\hline \multicolumn{2}{|l|}{ Occupation } \\
\hline Blue collar & $51(22.57)$ \\
\hline White collar & 75 (33.19) \\
\hline Unemployed & $73(32.30)$ \\
\hline Retired & 27 (11.95) \\
\hline Student & $0(0)$ \\
\hline \multicolumn{2}{|l|}{ Average monthly per capita income (CNY) } \\
\hline$<1,000$ & $20(8.85)$ \\
\hline $1,000-1,999$ & $38(16.81)$ \\
\hline $2,000-2,999$ & 77 (34.07) \\
\hline $3,000-3,999$ & $40(17.70)$ \\
\hline $4,000-4,999$ & $20(8.85)$ \\
\hline$\geq 5,000$ & $31(13.72)$ \\
\hline \multicolumn{2}{|l|}{ Residential address } \\
\hline Sichuan Province & 210 (93.36) \\
\hline Others & $15(6.64)$ \\
\hline \multicolumn{2}{|l|}{ Type of medical insurance (multiple choice) } \\
\hline Typical (town residents or employees) & $157(67.97)$ \\
\hline New rural cooperative medical system (NCMS) & $65(28.14)$ \\
\hline Commercial & $3(1.30)$ \\
\hline Others & $7(3.03)$ \\
\hline None & $1(0.43)$ \\
\hline
\end{tabular}

$\mathrm{BC}$, breast cancer.
Table 2 Medical history of women with BC

\begin{tabular}{lc}
\hline Characteristics & $\mathrm{n}=226(\%)$ \\
\hline Family history of BC & $12(5.31)$ \\
Yes & $214(94.69)$ \\
No & \\
Routine breast examination & $59(26.11)$ \\
Yes & $167(73.89)$ \\
No &
\end{tabular}

Symptom disclosure to others

Yes

189 (83.63)

No

37 (16.37)

Reasons for first medical consultation (multiple choice)

Fear about own illness

200 (78.43)

Proposal from others

$44(17.25)$

Physical examination

10 (3.92)

Others

$1(0.39)$

Hospital category for first medical consultation

Primary health institution

127 (56.19)

Tumor hospital

35 (15.49)

Comprehensive grade $3 \mathrm{~A}$ hospital

$64(28.32)$

Examinations for first medical consultation (multiple choice)

Mammography

$43(15.36)$

Color Doppler ultrasonography

212 (75.71)

Routine examination

$7(2.50)$

Fine needle aspiration cytology (FNAC)

$11(3.93)$

Others

$7(2.50)$

Reasons for not obtaining further confirmation (multiple choice)

Not painful, thought symptoms not serious

$171(57.58)$

Occupied by other life priorities

59 (19.87)

Treated by traditional Chinese medicine

$20(6.73)$

Awaiting medical appointments

$15(5.05)$

Others

$32(10.77)$

Reasons for this medical consultation (multiple choice)

Breast lump/pain

211 (69.64)

Fear

50 (16.50) 
Table 2 (continued)

\begin{tabular}{lc}
\hline Characteristics & $\mathrm{n}=226(\%)$ \\
\hline $\begin{array}{l}\text { Accidentally discovered under other medical } \\
\text { consultation }\end{array}$ & $8(2.64)$ \\
Axillary lump & $17(5.61)$ \\
Others & $17(5.61)$ \\
Staging of BC & \\
0 & $5(2.19)$ \\
I & $42(18.42)$ \\
IIA & $71(31.14)$ \\
IIB & $51(22.37)$ \\
IIIA & $29(12.72)$ \\
IIIB & $7(3.07)$ \\
IIIC & $4(1.75)$ \\
IV & $17(7.46)$ \\
Underlying disease & \\
Yes & $51(22.57)$ \\
No & $175(77.43)$ \\
\hline BC, &
\end{tabular}

$\mathrm{BC}$, breast cancer.

appraisal delay and patient delay accounted for a higher percentage in delay time 0-29 days and $>360$ days, as the proportion is $62.95 \%$ and $12.50 \%$ in appraisal delay, $50.89 \%$ and $14.29 \%$ in patient delay separately. The proportion (85.27\%) of women with 0-29 days of utilization delay was far higher than that of any other delay days (Table 3).

\section{Factors associated with appraisal, utilization, and patient delay}

Eight potential factors (e.g., age) that might affect the appraisal delay of women with BC and that were screened by univariate analysis (Table 4), were further analyzed by stepwise regression analysis. Consequently, the influential factors of appraisal delay $\left(\mathrm{y}_{1}\right)$ were found to be age $\left(\mathrm{x}_{1}\right)$, residential address $\left(\mathrm{x}_{2}\right)$, symptom disclosure to others $\left(\mathrm{x}_{3}\right)$, reasons for this medical consultation $\left(\mathrm{x}_{4}\right)$, and knowledge of BC $\left(\mathrm{x}_{5}\right)$. The direction and degree of the effect of these factors was determined by the following regression equation: $\mathrm{y}_{2}=193.40-3.80 \mathrm{x}_{1}-14.11 \mathrm{x}_{2}-4.92 \mathrm{x}_{3}+15.77 \mathrm{x}_{4}+2.38 \mathrm{x}_{5}$. In particular, reasons for medical consultation $\left[b_{4}=15.77\right.$, SE $\left.\left(b_{4}\right)=13.18\right]$ predicted a longer appraisal delay, while residential address $\left[b_{2}=-14.11\right.$, SE $\left.\left(b_{2}\right)=15.93\right]$ predicted a shorter one (Table 5).

Eight potential factors (e.g., number of children) that could affect utilization delay of women with BC and that were screened by univariate analysis (Table 4) were further analyzed by stepwise regression analysis. This analysis revealed that the influential factors of utilization delay $\left(\mathrm{y}_{2}\right)$ were number of children $\left(\mathrm{x}_{1}\right)$, routine breast examination $\left(\mathrm{x}_{2}\right)$, hospital category for first medical consultation $\left(\mathrm{x}_{3}\right)$, examinations for first medical consultation $\left(\mathrm{x}_{4}\right)$, reasons for not obtaining further confirmation $\left(\mathrm{x}_{5}\right)$, reasons for this medical consultation $\left(\mathrm{x}_{6}\right)$, underlying disease $\left(\mathrm{x}_{7}\right)$, and knowledge of $\mathrm{BC}\left(\mathrm{x}_{8}\right)$. These factors' directions and degree of the effect were determined by the following regression equation: $\mathrm{y}_{2}=74.99-3.16 \mathrm{x}_{1}-5.18 \mathrm{x}_{2}-2.14 \mathrm{x}_{3}-2.77 \mathrm{x}_{4}-$ $0.49 \mathrm{x}_{5}+0.66 \mathrm{x}_{6}-0.39 \mathrm{x}_{7}-0.68 \mathrm{x}_{8}$ (Table 5).

The same process was applied to 11 factors of patient delay $\left(y_{3}\right)$ for BC patients. Age $\left(\mathrm{x}_{1}\right)$, number of children $\left(\mathrm{x}_{2}\right)$, residential address $\left(\mathrm{x}_{3}\right)$, routine breast examination $\left(\mathrm{x}_{4}\right)$, symptom disclosure to others $\left(\mathrm{x}_{5}\right)$, reasons for not obtaining further confirmation $\left(\mathrm{x}_{6}\right)$, reasons for medical consultation $\left(\mathrm{x}_{7}\right)$, and knowledge of $\mathrm{BC}\left(\mathrm{x}_{8}\right)$ were identified as the influencing factors, with the following regression equation: $\mathrm{y}_{3}=242.16-4.91 \mathrm{x}_{1}+28.50 \mathrm{x}_{2}-20.98 \mathrm{x}_{3}-27.34 \mathrm{x}_{4}-$ $\left.97.17 \mathrm{x}_{5}-14.02 \mathrm{x}_{6}+14.56 \mathrm{x}_{7}+1.21 \mathrm{x}_{8}\right)$. Obviously, number of children $\left[\mathrm{b}_{2}=28.50\right.$, SE $\left.\left(\mathrm{b}_{2}\right)=39.02\right]$ and reasons for medical consultation $\left[b_{7}=14.56, \mathrm{SE}\left(\mathrm{b}_{7}\right)=13.35\right]$ predicted a longer patient delay for $\mathrm{BC}$ women, while symptom disclosure to others $\left[b_{5}=-97.17\right.$, SE $\left.\left(b_{5}\right)=67.51\right]$ predicted a shorter one (Table 5).

\section{Discussion}

The characteristics and related factors of patient delay for women with BC were examined and analyzed in this study. Patient delay is a key element of BC progression (14). Our questionnaire data indicated that one-third of $\mathrm{BC}$ women had over 90 days of patient delay; this delay is widely considered to seriously endanger health $(13,15)$. Patient delay was divided into appraisal delay and utilization delay for further analysis. The appraisal delay's time distribution of a higher percentage at delay time 0-29 and >360 days, while other delay time occupies lower percentage, which is highly consistent with that of patient delay, while utilization delay mainly occupies the period of 0-29 days. Thus, appraisal delay is the leading component of patient delay.

Older age, nearby residential address, routine breast examination, and greater symptom disclosure to others 


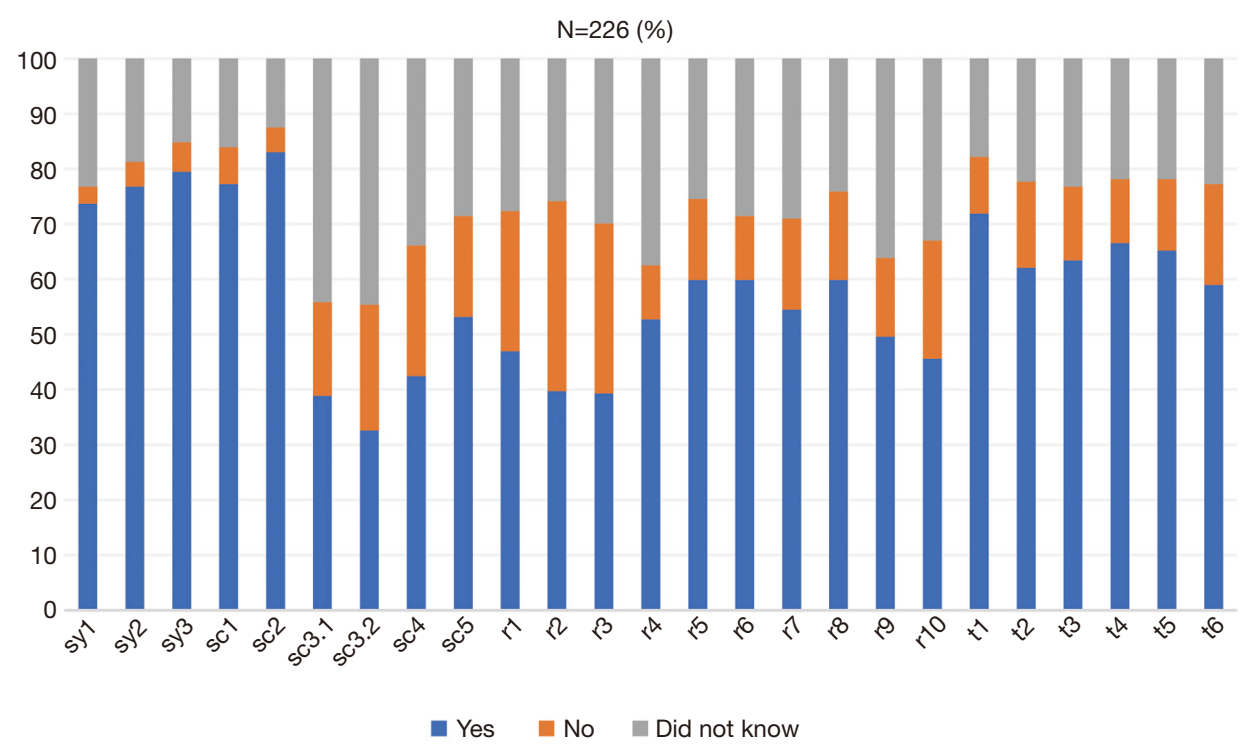

Figure 2 Knowledge of BC in women with BC. BC, breast cancer; sy1,"Will BC destroy normal tissue?" sy2, "Will BC proliferate?" sy3, "Is BC a malignant tumor?" sc1, "Do you think screening can detect BC early?" sc2, "Do you think early detection of BC improves survival?" sc3, "Do you know about the time of breast self-examination?" sc4, "Do you know about the technique of breast self-examination?" sc5, "Do you consider mammography to be a screening method for BC?" sc6, "Do you consider a doctor's examination to be a screening method for $\mathrm{BC}$ ?" $\mathrm{r} 1$, "Is the occurrence of BC is related to age?" $\mathrm{r} 2$, "Is the occurrence of BC is related to heredity?" $\mathrm{r} 3$, "Is the occurrence of BC is related to obesity?" $\mathrm{r} 4$, "Is the occurrence of $\mathrm{BC}$ is related to endocrine disorder?" $\mathrm{r} 5$, "Is the occurrence of $\mathrm{BC}$ is related to unhealthy lifestyle?" r6, "Is the occurrence of BC is related to prior BC in the other side?" r7, "Is the occurrence of BC is related to benign breast disease?" $\mathrm{r} 8$, "Is the occurrence of $\mathrm{BC}$ is related to exposure to high doses of radiation or prolonged environmental contamination?" $\mathrm{r} 9$, "Is the occurrence of $\mathrm{BC}$ is related to estrogen?" $\mathrm{r} 10$, "Is the occurrence of BC is related to number of pregnancies, age of bearing or duration of lactation?" t1, "Do you regard breast lump as typical symptoms and signals of BC?" t2, "Do you regard axillary lump as typical symptoms and signals of BC?" t3, "Do you regard breast pain as typical symptoms and signals of BC?" t4, "Do you regard nipple change as typical symptoms and signals of BC?" t5, "Do you regard shape change of breast as typical symptoms and signals of BC?" t6, "Do you regard skin change of breast as typical symptoms and signals of BC?".

Table 3 Delay of medical consultation of women with BC

\begin{tabular}{lccc}
\hline \multirow{2}{*}{ Day(s) } & \multicolumn{3}{c}{$\mathrm{n}=226(\%)$} \\
\cline { 2 - 4 } & Appraisal delay & Utilization delay & Patient delay \\
\hline $0-29$ & $141(62.95)$ & $191(85.27)$ & $114(50.89)$ \\
$30-59$ & $13(5.80)$ & $13(5.80)$ & $21(9.38)$ \\
$60-89$ & $8(3.57)$ & $7(3.13)$ & $14(6.25)$ \\
$90-179$ & $15(6.70)$ & $7(3.13)$ & $25(11.16)$ \\
$180-359$ & $19(8.48)$ & $1(0.45)$ & $18(8.04)$ \\
$360+$ & $28(12.50)$ & $5(2.23)$ & $32(14.29)$ \\
\hline
\end{tabular}

$\mathrm{BC}$, breast cancer.

led to a decrease of appraisal/patient delay for women with BC. However, reasons for this medical consultation and knowledge of BC prolonged appraisal/patient delay. This may be because the time for patients who are retired or unemployed and who are keen to acquire health information may increase as they age. It is also possible that the women with lower education confused their answers with the present symptoms and thus confirmed the symptom questions in the questionnaires when filling. Such as it is, women with BC have less knowledge related to the risk factors and screening-which are key parts of the problem-than they do of basic knowledge, typical symptoms, and signs of BC. Many factors related to hospitals, such as hospital category for first medical consultation and examinations for first medical consultation, could reduce utilization delay. Meanwhile, the number of child and knowledge of BC, which increases the likelihood of symptom disclosure to others to some extent, could also 
Table $4 \mathrm{P}$ value of univariate analysis on all factors affecting delay of medical consultation of women with BC

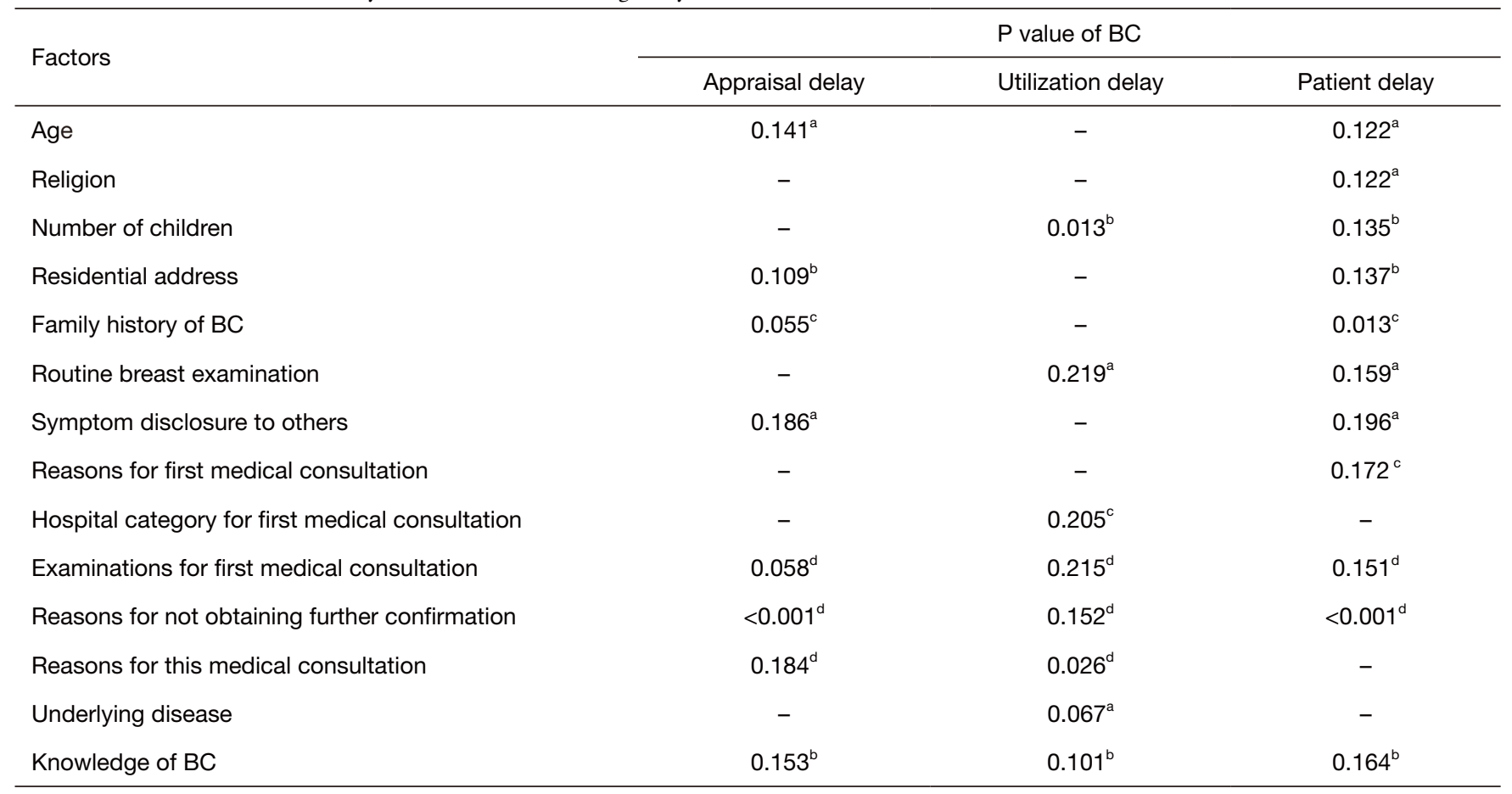

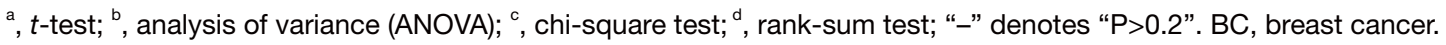

prolong utilization delay time.

In short, symptom disclosure to others and knowledge of BC play important roles in patient delay of women with BC. For one, the overall outcome of symptom disclosure to others, indicating social support from family members, immediate partners and friends, was reported by some studies to be positive for women, in that it led to informational and emotional support (16-22). Mohadesi et al. (23) also stated that social and emotional support from a spouse or family members of patients with $\mathrm{BC}$ can reduce mental distress experienced during the diagnosis process. Meanwhile, obstacles should be removed so as to prevent the progression of $\mathrm{BC}$ for younger patients who are usually occupied by work or other life priorities. Lam et al. (21) found that competing priorities, such as work and family commitments, can act as barriers to seeking medical help in some participants. Maintaining health should be understood as a necessary prerequisite for performing other daily duties, and personal responsibilities should not act as a barrier to seeking medical help. Therefore, logistical problems for working women should be resolved to decrease prolonged medical consultation, especially those with higher education who have competing work commitments and do not give proper attention to health demands (19).
A large number of studies on patient delay in $\mathrm{BC}$ and delay-related factors have been published in recent years $(14,16,21,24)$. It has been found that women's fear of cancer and their prolonged patient delay usually results in patients' being in the middle or even advanced phase of the $\mathrm{BC}$ once finally diagnosed (25). In line with this, women with $\mathrm{BC}$ of IIA and IIB account for $53.51 \%$ of the cases in this study, which is indeed an ominous sign. Even with early detection, the mental burden to patients and living under the shadow of cancer will have an unfavorable influence on the control of disease. The symptoms of BC are easily ignored by patients without specialized knowledge, and the prolonged patient delay increases the risk of malignant transformation.

In addition, people are more vulnerable to diseases and suffer from worse emotional and psychological problems as they increase in age. Hence, the knowledge of the risk factors and screening methods of $\mathrm{BC}$ also needs strengthening for women with $\mathrm{BC}$ to avoid these complex delay-related factors as they age. Physical examination may be helpful in breast cancer screening, but there is no evidence that it can improve early diagnosis of breast cancer and reduce its mortality. Some measurements, such as preventive publicity and routine breast examination, for early diagnosis and treatment of breast diseases may 
Table 5 Regression results of appraisal, utilization, and patient delay

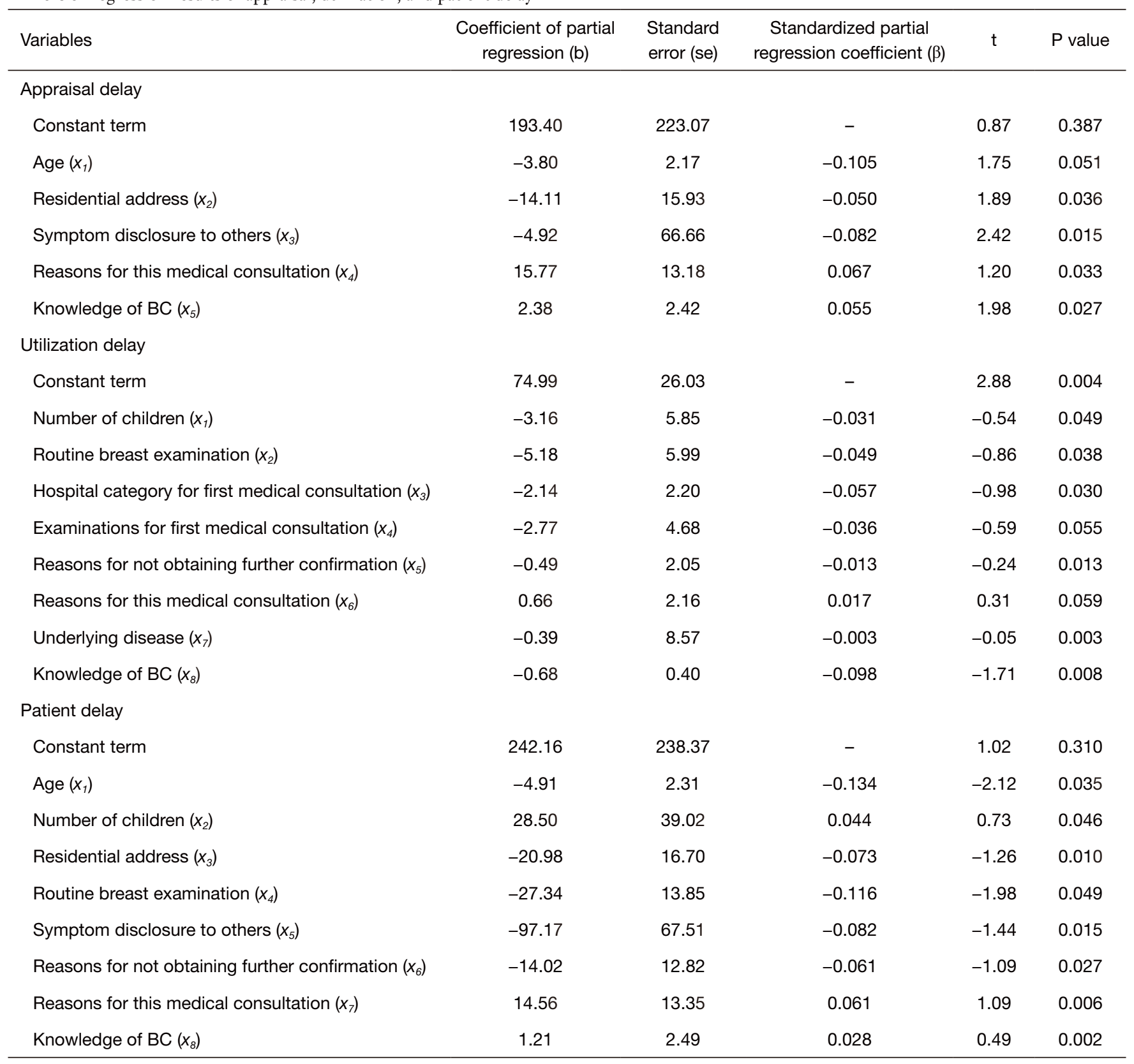

$\mathrm{BC}$, breast cancer.

be targeted and effective, and have been recommended by Gangane et al. (2). These researchers claimed that only $6.6 \%$ of women in their study of 384 cases in India had heard about breast self-examination, and thus there needs to be a better policy to focus on education and convey the positive message that BC is treatable. Every year, October is named as Breast Cancer Awareness Month, during which international health campaign lasting the whole month. Breast cancer health education cannot be limited to the awareness month, but can also be carried out in daily life. Organizations, medical societies and government agencies can work together to improve public awareness about breast cancer through textbooks, community education, new media as well as oriented education. Because of the cost 
and uncertainty surrounding BC screening, the emphasis should be concentrated on prevention. There are many screening measures for breast cancer including annual visits to specialists for physical examination, breast selfexamination, mammogram, ultrasound, and breast MRI. It has been shown that screening mammography can reduce at least $20 \%$ breast cancer mortality by eight RCT (randomized clinical trials) (26). And the positive predictive value of ultrasonography and MRI screening is $3-8 \%$ and $90-93 \%$, separately (27-29). But we should concentrate on prevention. And BC prevention includes etiological prevention like surgery, medication and lifestyle options for women at increased risk for BC (30), secondary and tertiary prevention. Avoidance of hormonal therapy, late pregnancy, low number of births or no pregnancy, advanced age at first full-term delivery, and living a healthy lifestyle could decrease the risk of BC (31,32). Early detection, diagnosis and treatment can improve the cure and survival rates. Moreover, their study indicated that clearing barriers of utilization delay in primary health institutions should also be taken into consideration.

Our retrospective study spanned over 5 years, which might have introduced some bias. Our survey was chosen to be done when patients were in the outpatient clinic for a waiting visit, having minimized artificial bias. With a duration of 5 years, there may indeed be a gap in the population's level of breast cancer knowledge. We had explained the options and some knowledge about breast diseases to the patients in detail to minimize the influence of understanding errors on the questionnaire results before they filled out the questionnaire. We could continue such a study at a later stage, grouping by year of inclusion and analyzing whether the year of inclusion affects the results. As reported, menopausal changes can confound detection of suspicious symptoms (25). Furthermore, married or cohabiting patients had higher scores in the quality of life than those who were living alone or divorced. This could be explained by the financial and emotional support provided to patients by their immediate partners $(33,34)$. Both of these phenomena were not considered in this study and need to be further explored in future research. Moreover, women with a high fear of cancer diagnosis may be more likely to use avoidant coping and therefore may delay seeking medical consultation, but these psychological factors were not taken into account in our analysis. Meanwhile, no collection statistics about survival were performed in our study because the initial treatment modality of patients in our study included post-surgical chemotherapy and neoadjuvant chemotherapy followed by surgery, the time from diagnosis to surgery in our center was basically controlled within 2 weeks for those treated with post-surgical chemotherapy. Women meeting the inclusion and exclusion criteria were enrolled between April 20, 2014 and June 20, 2019 in our study, the fellow-up time is short for some patients. Thus, there are limitations in our study, we are looking forward to get the long fellow-up data of those women included to illustrate how the patient delay affect the OS and DFS in our study.

Nonetheless, this study has advantages over previous patient delay studies, in that we recruited women before the confirmation of $\mathrm{BC}$ diagnosis, which avoided the effects of rationalization in help-seeking behavior, and distortion or misrepresentation of symptom duration and decision making (35). Using a regression equation to present how these factors interact to influence patients' help-seeking decisions will advance our understanding in the patient delay of women with BC. Above all, it is critical that costeffective interventions, such as enhancing social support and perception of knowledge on $\mathrm{BC}$, be implemented for early BC detection in Sichuan Province, China, which may act as a model for other places in the future.

\section{Acknowledgments}

We would like to thank J. Gray for English language editing.

Funding: This study was sponsored by Wu Jieping Medical Foundation (320.6750.2020-07-7).

\section{Footnote}

Reporting Checklist: The authors have completed the STROBE reporting checklist. Available at https://dx.doi. org/10.21037/gs-21-227

Data Sharing Statement: Available at https://dx.doi. org/10.21037/gs-21-227

Conflicts of Interest: All authors have completed the ICMJE uniform disclosure form (available at https://dx.doi. org/10.21037/gs-21-227). The authors have no conflicts of interest to declare.

Ethical Statement: The authors are accountable for all aspects of the work in ensuring that questions related to the accuracy or integrity of any part of the work are 
appropriately investigated and resolved. All procedures performed in this study involving human participants were in accordance with the Declaration of Helsinki (as revised in 2013). The study was approved by Ethical Committee of Sichuan Cancer Hospital (No.: SCCHEC-02-2021-033) and informed consent was taken from all the patients.

Open Access Statement: This is an Open Access article distributed in accordance with the Creative Commons Attribution-NonCommercial-NoDerivs 4.0 International License (CC BY-NC-ND 4.0), which permits the noncommercial replication and distribution of the article with the strict proviso that no changes or edits are made and the original work is properly cited (including links to both the formal publication through the relevant DOI and the license). See: https://creativecommons.org/licenses/by-nc-nd/4.0/.

\section{References}

1. Torre LA, Bray F, Siegel RL, et al. Global cancer statistics, 2012. CA Cancer J Clin 2015;65:87-108.

2. Gangane N, Anshu, Manvatkar S, et al. Prevalence and Risk Factors for Patient Delay Among Women With Breast Cancer in Rural India. Asia Pac J Public Health 2016;28:72-82.

3. Ye LJ, Suo HD, Liang CY, et al. Nomogram for predicting the risk of bone metastasis in breast cancer: a SEER population-based study. Transl Cancer Res 2020;9:6710-9.

4. Caplan LS, Helzlsouer KJ. Delay in breast cancer: a review of the literature. Public Health Rev 1992-1993;20:187-214.

5. Andersen BL, Cacioppo JT. Delay in seeking a cancer diagnosis: delay stages and psychophysiological comparison processes. Br J Soc Psychol 1995;34 ( Pt 1):33-52.

6. Fan L, Strasser-Weippl K, Li JJ, et al. Breast cancer in China. Lancet Oncol 2014;15:e279-89.

7. Bleicher RJ, Ruth K, Sigurdson ER, et al. Time to Surgery and Breast Cancer Survival in the United States. JAMA Oncol 2016;2:330-9.

8. Mateo AM, Mazor AM, Obeid E, et al. Time to Surgery and the Impact of Delay in the Non-Neoadjuvant Setting on Triple-Negative Breast Cancers and Other Phenotypes. Ann Surg Oncol 2020;27:1679-92.

9. Richards MA, Westcombe AM, Love SB, et al. Influence of delay on survival in patients with breast cancer: a systematic review. Lancet 1999;353:1119-26.

10. Burgess CC, Potts HW, Hamed H, et al. Why do older women delay presentation with breast cancer symptoms? Psychooncology 2006;15:962-8.
11. Friedman LC, Kalidas M, Elledge R, et al. Medical and psychosocial predictors of delay in seeking medical consultation for breast symptoms in women in a public sector setting. J Behav Med 2006;29:327-34.

12. Rauscher GH, Ferrans CE, Kaiser K, et al. Misconceptions about breast lumps and delayed medical presentation in urban breast cancer patients. Cancer Epidemiol Biomarkers Prev 2010;19:640-7.

13. Montella M, Crispo A, Botti G, et al. An assessment of delays in obtaining definitive breast cancer treatment in Southern Italy. Breast Cancer Res Treat 2001;66:209-15.

14. Attari SM, Ozgoli G, Solhi M, et al. Study of Relationship Between Illness Perception and Delay in Seeking Help for Breast Cancer Patients Based on Leventhal's SelfRegulation Model. Asian Pac J Cancer Prev 2016;17:167-74.

15. Kailemia PN, Lee EC, Taylor C, et al. Exploring determinants of, and interventions for, delayed presentation of women with breast symptoms: A systematic review. Eur J Oncol Nurs 2020;44:101677.

16. Khakbazan Z, Taghipour A, Latifnejad Roudsari R, et al. Help seeking behavior of women with self-discovered breast cancer symptoms: a meta-ethnographic synthesis of patient delay. PLoS One 2014;9:e110262.

17. Abdullah A, Abdullah KL, Yip CH, et al. The decisionmaking journey of malaysian women with early breast cancer: a qualitative study. Asian Pac J Cancer Prev 2013;14:7143-7.

18. O'Mahony M, Hegarty J, McCarthy G. Women's help seeking behaviour for self discovered breast cancer symptoms. Eur J Oncol Nurs 2011;15:410-8.

19. Unger-Saldaña K, Infante-Castañeda CB. Breast cancer delay: a grounded model of help-seeking behaviour. Soc Sci Med 2011;72:1096-104.

20. Lu MH, Lin HR, Lee MD. The experiences among older Taiwanese women facing a new diagnosis of breast cancer. Cancer Nurs 2010;33:398-405.

21. Lam WW, Tsuchiya M, Chan M, et al. Help-seeking patterns in Chinese women with symptoms of breast disease: a qualitative study. J Public Health (Oxf) 2009;31:59-68.

22. Burgess C, Hunter MS, Ramirez AJ. A qualitative study of delay among women reporting symptoms of breast cancer. Br J Gen Pract 2001;51:967-71.

23. Mohadesi H, Ayatollahi H, HasanZadeh G, et al. Quality of life in breast cancer patients: Study in the Omid cancer research center-Urmia. Iran J Breast Dis 2013;5:35-43.

24. Gangane N, Khairkar P, Hurtig AK, et al. Quality of Life 
Determinants in Breast Cancer Patients in Central Rural India Asian Pac J Cancer Prev 2017;18:3325-32.

25. Li WW, Lam WW, Wong JH, et al. Waiting to see the doctor: understanding appraisal and utilization components of consultation delay for new breast symptoms in Chinese women. Psychooncology 2012;21:1316-23.

26. Oeffinger KC, Fontham ET, Etzioni R, et al. Breast Cancer Screening for Women at Average Risk: 2015 Guideline Update From the American Cancer Society. JAMA 2015;314:1599-614.

27. Melnikow J, Fenton JJ, Whitlock EP, et al. Supplemental Screening for Breast Cancer in Women With Dense Breasts: A Systematic Review for the U.S. Preventive Services Task Force. Ann Intern Med 2016;164:268-78.

28. Kuhl C, Weigel S, Schrading S, et al. Prospective multicenter cohort study to refine management recommendations for women at elevated familial risk of breast cancer: the EVA trial. J Clin Oncol 2010;28:1450-7.

29. Sardanelli F, Podo F, Santoro F, et al. Multicenter surveillance of women at high genetic breast cancer risk using mammography, ultrasonography, and contrastenhanced magnetic resonance imaging (the high breast cancer risk italian 1 study): final results. Invest Radiol

Cite this article as: Li B, Xia L, Yang J, Wen M, Yu M, Mou E, Liu S, Li H, Wang H. Enhancing social support and knowledge perception decreases patient delay in breast cancer. Gland Surg 2021;10(7):2220-2231. doi: 10.21037/gs-21-227
2011;46:94-105.

30. Britt KL, Cuzick J, Phillips KA. Key steps for effective breast cancer prevention. Nat Rev Cancer 2020;20:417-36.

31. Nur U, El Reda D, Hashim D, et al. A prospective investigation of oral contraceptive use and breast cancer mortality: findings from the Swedish women's lifestyle and health cohort. BMC Cancer 2019;19:807.

32. Deshmukh SK, Srivastava SK, Poosarla T, et al. Inflammation, immunosuppressive microenvironment and breast cancer: opportunities for cancer prevention and therapy. Ann Transl Med 2019;7:593.

33. Yan B, Yang LM, Hao LP, et al. Determinants of Quality of Life for Breast Cancer Patients in Shanghai, China. PLoS One 2016;11:e0153714.

34. Broeckel JA, Jacobsen PB, Balducci L, et al. Quality of life after adjuvant chemotherapy for breast cancer. Breast Cancer Res Treat 2000;62:141-50.

35. Facione NC, Giancarlo C, Chan L. Perceived risk and help-seeking behavior for breast cancer. A ChineseAmerican perspective. Cancer Nurs 2000;23:258-67.

(English Language Editor: J. Gray) 